\title{
Diabetes mellitus among patients attending TB clinics in Dar es Salaam: a descriptive cross-sectional study
}

\author{
Patricia J. Munseri ${ }^{*}$ D, Henrika Kimambo ${ }^{\dagger}$ and Kisali Pallangyo
}

\begin{abstract}
Background: A bi-directional interaction between diabetes mellitus and tuberculosis is well established and has been likened to that between HIV and TB. Whereas HIV screening is standard of care test in sub Saharan Africa TB programs, the same is not true for diabetes mellitus (DM). Sub Saharan Africa, a region with high TB infection rates, is going through an epidemiological transition with rapidly rising prevalence of diabetes.

We aimed at characterizing TB patients with DM in order to identify factors associated with TB-DM dual disease among patients attending TB clinics in Dar es Salaam.

Methods: A cross-sectional study was conducted between September 2016 and January 2017 among patients attending TB clinics in Dar es Salaam. We collected socio-demographic characteristics, anthropometric measurements and screened for diabetes by measuring fasting blood glucose that was followed by a $2 \mathrm{~h}$ postprandial glucose for participants with impaired fasting blood glucose. We examined for socio-demographic and clinical factors associated with diabetes using logistic regression analysis.
\end{abstract}

Results: Of the 660 enrolled participants with TB, 25 (3.8\%) were on treatment for diabetes while 39 (6.1\%) and 147 (23\%) of the remaining 635 participants were ultimately diagnosed with DM and impaired fasting blood glucose respectively. The overall prevalence of DM was 9.7\% (64/660). Independent risk factors for diabetes included: age > 44 years \{OR 4.52, 95\% Cl: [1.28-15.89]\}; family history of diabetes \{OR 3.42, 95\% [Cl 1.88-6.21]\}.

HIV sero-positive TB patients were less likely to have DM compared to those who were HIV sero-negative \{OR 0.35 , $95 \% \mathrm{Cl}[0.17-0.73]\}$.

Conclusions: Screening for diabetes should be advocated for TB patients aged above 44 years and/or with a family history of diabetes. HIV sero-negative TB patients were more likely to have DM compared to those who were HIV sero-positive. Further studies are needed to confirm this observation and the underlying factors.

Keywords: Diabetes mellitus, Tuberculosis, Screening, Routine care, Tanzania

\section{Introduction}

The prevalence of diabetes worldwide has increased by about $20 \%$ in the past three decades with particularly large rates in low and middle income countries [1, 2]. The International Diabetes Federation (IDF) predicts further increase in prevalence of DM especially in developing countries in the foreseeable future due to changes in life style, eating habits and other risk factors [3].

\footnotetext{
* Correspondence: patricia.munseri@gmail.com

${ }^{\dagger}$ Patricia J. Munseri and Henrika Kimambo contributed equally to this work. Department of Internal Medicine, Muhimbili University of Health and Allied Sciences Dar es Salaam, Box 65315, Dar es Salaam, Tanzania
}

Indeed countries in sub Saharan Africa (SSA), are going through an epidemiological transition with rising prevalence of non-communicable diseases including type two DM (T2DM) [4]. For example between the 1980s and 2010 the prevalence of DM in rural Tanzania increased from 0.9 to $5 \%[5,6]$. Furthermore data from the city of Dar- es -salaam indicates that the prevalence of DM among the general population increased from $<2$ to 9.1\% during the period of 1980-2012 [5, 6]. A bidirectional interaction between DM and Tuberculosis is well established [7]. People with DM are three times at risk of developing $\mathrm{TB}$ disease compared to non-diabetics

(C) The Author(s). 2019 Open Access This article is distributed under the terms of the Creative Commons Attribution 4.0 International License (http://creativecommons.org/licenses/by/4.0/), which permits unrestricted use, distribution, and reproduction in any medium, provided you give appropriate credit to the original author(s) and the source, provide a link to the Creative Commons license, and indicate if changes were made. The Creative Commons Public Domain Dedication waiver (http://creativecommons.org/publicdomain/zero/1.0/) applies to the data made available in this article, unless otherwise stated. 
[8]. Glucose intolerance or transient hyperglycemia has been observed in up to $49 \%$ of patients with active TB [9]. Patients with DM have impaired cellular immunity and ciliary function that predisposes them to $\mathrm{TB}$ while stress response to $\mathrm{TB}$ may result to insulin resistance. TB disease of the pancreas can lead to endocrine hypofunction with consequent DM [7]. In addition DM is an independent risk factor for poor TB treatment response as well as death $[10,11]$. In 2015 the IDF reported that $66.7 \%$ of people with diabetes in SSA are unaware that they have the disease [3].

Tanzania is a high TB endemic country with reported prevalence rates of 293 cases per 100,000 for individuals aged 15-64 years and 709 cases per 100,000 for individuals above 65 years of age [12]. Hence the rising prevalence of DM is likely to have significant negative impact on TB control and has been likened to the impact of HIV on TB control [13].

Consequently, screening TB patients for DM and vice versa should result in better control of both diseases, as this would aid in early detection and treatment that would result in better outcomes. Indeed, routine screening of $\mathrm{TB}$ patients for $\mathrm{DM}$ using $\mathrm{HbA1c}$ in India by Balachrishnan et al. found that over $40 \%$ had diabetes [14]. However, Balachrisnan and colleagues did not advocate routine DM screening using HbA1c but recommended further operational research be performed to determine the most cost- effective ways of diabetes screening.

We aimed at determining the prevalence of DM among TB patients and characterizing TB patients with DM in order to identify factors associated with TB-DM dual disease among patients attending $\mathrm{TB}$ treatment clinics in Dar es Salaam, Tanzania.

\section{Methods}

\section{Ethics statement}

Ethical approval was obtained from the Muhimbili University of Health and Allied Science institutional review board approval number MU/PGS/SAEC/Vol.XVI/. All recruited participants were informed about the study details prior to enrollment and verbal consent was obtained from each study participant prior to enrollment in the study. Patients who were newly diagnosed with diabetes during this study were referred to a diabetic clinic to receive standard of care treatment for diabetes.

\section{Study design and population}

This descriptive cross-sectional study was conducted in four TB clinics in Dar es Salaam, Tanzania from September 2016 to January 2017. Each clinic represents one of the three districts in Dar es Salaam and receives about 30 TB patients per day. Consecutive patients on treatment for tuberculosis aged 18 years or above attending the four clinics at the time of the study were eligible and consenting patients were enrolled into the study. Recruited participants were either newly diagnosed TB patients or patients who were continuing with TB treatment.

\section{Data collection}

Data was collected using an interviewer based structured questionnaire. A research assistant conducted face to face interviews and physical examination. Information collected included socio-demographic characteristics, symptom screening for diabetes, factors associated with type 2 diabetes including alcohol consumption, cigarette smoking and a past medical history related to diabetes. Smoking was categorized as ever smoked in a lifetime or never smoked, Alcohol intake was categorized as ever taken alcohol or never taken alcohol in their lifetime.

We also collected information on sputum smear status, TB anatomical site, TB treatment category, and HIV status from the participants TB treatment cards.

We measured the participant's weight and height using standard equipment based at the TB clinics thereafter computed body mass index (BMI). BMI was computed as the participant's weight in kilograms divided by the participant's height in meters squared. BMI was grouped into four categories as follows; BMI of $<18.5$ was regarded as underweight, 18.5-24.9 normal weight, 25.0-29.9 overweight and a BMI > 20.9 was regarded as obese $[15,16]$.

A capillary fingertip blood sample was collected from each patient for fasting blood glucose. All participants with impaired fasting blood glucose were given $75 \mathrm{mg}$ of oral glucose that was followed by a two-hour postprandial blood glucose measurement using standard ACCU-CHECK blood glucose meter. The American Diabetic Association (ADA) diagnostic criteria were used for diagnosis of diabetes [17]. Diabetes was defined as either a fasting blood glucose level of $>6.9 \mathrm{mmol} / \mathrm{L}$ or a 2$\mathrm{h}$ postprandial glucose level of $\geq 11.1 \mathrm{mmol} / \mathrm{L}$ while impaired fasting glucose was defined as glucose levels of $5.6 \mathrm{mmol} / \mathrm{L}-6.9 \mathrm{mmol} / \mathrm{L}[18]$.

\section{Statistical methods}

The total number of participants recruited to estimate the prevalence of diabetes was based on the sample size estimation formula with an estimated prevalence of diabetes among TB patients to be $16.7 \%$ [19], type I error at 5 and $3 \%$ precision that amounted to 594 participants.

Data was transferred from the questionnaires and entered into SPPS version 23.0 database for cleaning and analysis. Continuous variables were summarized and presented as mean and standard deviation while categorical variables were summarized as proportions. Univariate and multivariate logistic regression analysis was 
Table 1 Socio-demographic characteristics of study participants $(N=660)$

\begin{tabular}{|c|c|c|}
\hline Characteristic & $n$ & $\%$ \\
\hline \multicolumn{3}{|l|}{ Sex } \\
\hline Male & 416 & 63 \\
\hline Female & 244 & 37 \\
\hline \multicolumn{3}{|l|}{ Age groups (years) } \\
\hline$\leq 24$ & 87 & 13.2 \\
\hline $25-34$ & 181 & 27.4 \\
\hline $35-44$ & 172 & 26.1 \\
\hline$\geq 45$ & 220 & 33.3 \\
\hline \multicolumn{3}{|l|}{ Highest education level } \\
\hline No formal education & 65 & 9.8 \\
\hline Primary & 430 & 65.2 \\
\hline Secondary & 121 & 18.3 \\
\hline College & 44 & 6.7 \\
\hline \multicolumn{3}{|l|}{ Marital Status } \\
\hline Single & 188 & 28.5 \\
\hline Married & 355 & 53.8 \\
\hline Divorced & 117 & 17.7 \\
\hline \multicolumn{3}{|l|}{ Occupation } \\
\hline Unemployed & 145 & 22 \\
\hline Employed & 484 & 73.3 \\
\hline Retired & 31 & 4.7 \\
\hline \multicolumn{3}{|l|}{ Family history of diabetes } \\
\hline Yes & 116 & 17.6 \\
\hline \multicolumn{3}{|l|}{ Cigarette smoking } \\
\hline Ever smoked & 180 & 27.3 \\
\hline \multicolumn{3}{|l|}{ Alcohol use } \\
\hline Ever used & 267 & 40.5 \\
\hline
\end{tabular}

performed to examine for factors that were associated with the outcome (diabetes mellitus) using Pearson's chi square test. All covariates with a $p$ value of $<0.2$ in univariate analysis, and confounders such as age, were entered in the multivariate analysis model based on literature [20]. As the symptoms for diabetes such as polyuria, nocturia, polyphagia and polydipsia were correlated we summarized these factors into one composite variable that was labeled any symptom for diabetes. Statistical significance was set at a $p$ value $<0.05$. For the multivariate and univariate model, risks were calculated and summarized as odds ratios and $95 \%$ confidence intervals significance level was set as a $p$ value of $<0.05$ in the multivariate analysis model.

\section{Results}

Socio-demographic and clinical characteristics

During the study period we recruited 660 participants out of 678 who were on TB treatment, 18 (2.6\%) of the participants withheld their consent, 416 (63\%) were
Table 2 Clinical characteristics of study participants $(N=660)$

\begin{tabular}{|c|c|c|}
\hline Characteristic & $\mathrm{n}$ & $\%$ \\
\hline \multicolumn{3}{|l|}{ Body mass Index $\mathrm{Kg} / \mathrm{M}^{2}$} \\
\hline Underweight & 173 & 26.3 \\
\hline Normal & 398 & 60.4 \\
\hline \multicolumn{3}{|l|}{ Missing $(n=1)^{\mathrm{a}}$} \\
\hline Overweight & 66 & 10.0 \\
\hline Obesity & 22 & 3.3 \\
\hline Polyuria & 110 & 16.7 \\
\hline Polyphagia & 68 & 10.3 \\
\hline Polydipsia & 82 & 12.4 \\
\hline Nocturia & 151 & 22.9 \\
\hline Loss of weight & 479 & 72.6 \\
\hline Fatigue & 375 & 56.8 \\
\hline Blurred vision & 100 & 15.2 \\
\hline \multicolumn{3}{|c|}{ Fasting blood glucose levels in mmol/L (n-635) } \\
\hline Normal & 453 & 71.3 \\
\hline Impaired fasting glucose & 147 & 23.1 \\
\hline Diabetes & 35 & 5.5 \\
\hline \multicolumn{3}{|c|}{ Oral glucose tolerance test $(n=147)$} \\
\hline Normal & 110 & 74.1 \\
\hline Impaired glucose tolerance & 33 & 23.1 \\
\hline Diabetes & 4 & 2.8 \\
\hline \multicolumn{3}{|l|}{ Sputum Acid fast bacilli status } \\
\hline Positive & 398 & 60.3 \\
\hline \multicolumn{3}{|l|}{ Tuberculosis anatomical site } \\
\hline Pulmonary & 577 & 87.4 \\
\hline \multicolumn{3}{|l|}{ TB treatment category } \\
\hline First line & 578 & 87.6 \\
\hline First line re-treatment & 68 & 10.3 \\
\hline Second line & 14 & 2.1 \\
\hline \multicolumn{3}{|l|}{ Tuberculosis treatment phase } \\
\hline Intensive & 269 & 40.8 \\
\hline Continuation & 391 & 59.2 \\
\hline \multicolumn{3}{|l|}{ HIV sero-status } \\
\hline Positive & 212 & 32.1 \\
\hline \multicolumn{3}{|l|}{ On HIV treatment } \\
\hline Yes & 191 & 90.1 \\
\hline
\end{tabular}

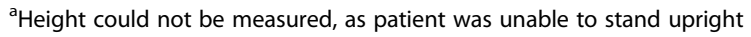

males. The mean age and standard deviation of the study population was $39.2 \pm 14.3$ years and the mean body mass index was $21.0 \mathrm{~kg} / \mathrm{m}^{2}$. One hundred and sixteen $(17.6 \%)$ participants had a positive family history of DM and 25 (3.8\%) participants were on treatment for diabetes mellitus. Other socio-demographic characteristics are summarized in Table 1. 


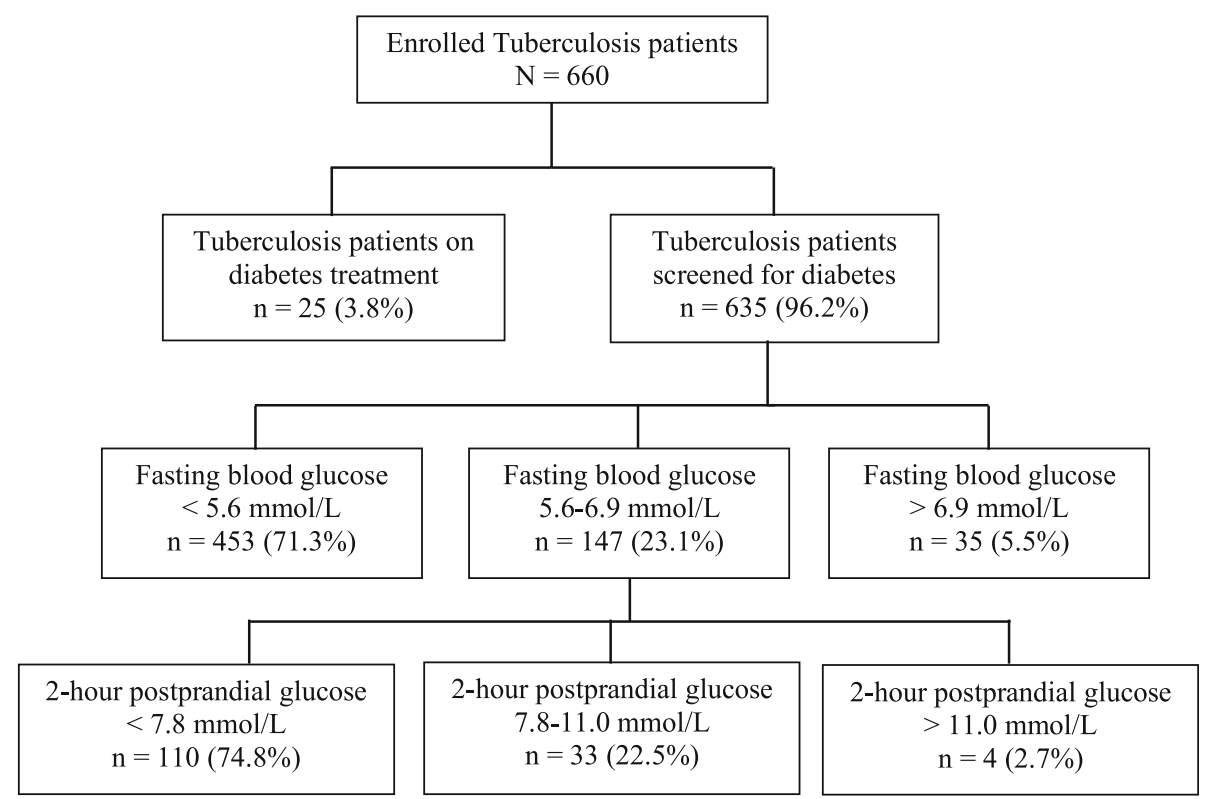

Fig. 1 Consort diagram showing the flow of participants

A total of $212(32 \%)$ participants had TB/HIV coinfection and 191 (90\%) of them were on HIV treatment. Of the enrolled participants 577 (87.4\%) had pulmonary tuberculosis and $389(60.3 \%)$ were smear positive for acid-fast bacilli as shown in Table 2 .

\section{Prevalence of diabetes mellitus}

A consort diagram Fig. 1, summarizes the flow of study participants. Of the 660 enrolled study participants with TB, 25 (3.8\%) were on treatment for DM and therefore the remaining 635 (96.2\%) participants were screened for DM. Out of the 635 participant who were screened 35 (5.5\%) were diagnosed to have DM with a fasting blood glucose of $>6.9 \mathrm{mmol} / \mathrm{L}$ and 147 (23.1\%) had an impaired fasting blood glucose (fasting blood glucose between $5.6-6.9 \mathrm{mmol} / \mathrm{L}$ ). The 147 study participants with impaired fasting blood glucose underwent a two-hour post-prandial oral glucose tolerance test, 4 (2.7\%) were diagnosed with diabetes and 33 (22.5\%) had impaired oral glucose tolerance test. Therefore, the overall prevalence of DM among the study participants with TB was 9.7\% (64/660), 95\% CI (7.4-12.0\%) while the prevalence of newly diagnosed DM among the study participants was $6.1 \%$. Impaired fasting blood glucose was detected in $23.1 \%(147 / 635) 95 \%$ CI (19.6-26.6).

\section{Factors associated with DM in TB patients}

Table 3 summarizes the factors associated with DM, age of $>44$ years was associated with a higher prevalence (15.9\%) of diabetes among TB patients $(p<0.001)$. and a family history of diabetes mellitus was significantly associated with a higher prevalence of DM (20.7\% vs $7.4 \%)$ $p<0.001$. DM was more prevalent in TB patients who were overweight and obese each accounting to $18 \%$ compared to patients who were underweight $7.5 \%$ or of normal weight $8.5 \%(p=0.031)$. Among the 64 diabetic patients with TB, 55 (9.5\% were categorized as new TB cases, 7 (10.8\%) were relapse TB and 2 (14.3\%) were drug resistant TB. There was no association between DM and clinical type of TB or results of sputum smear for acid-fast bacilli (data not shown).

\section{Predictors for DM in patients with TB}

The predictors for diabetes in patients with $\mathrm{TB}$ were as summarized in Table 4. In univariate analysis factors that were associated with an increased risk for diabetes were: any symptom for diabetes (polyphagia, polydipsia, polyuria or nocturia) \{OR 2.25 (95\% CI: 1.33-3.18)\}, blurring of vision $\{\mathrm{OR} 2.45$ (95\% CI: 1.36-4.44)\}, a family history of diabetes $\{\mathrm{OR} 3.29$ (95\% CI: 1.89-5.71) $\}$ and overweight \{OR 2.73 (95\%CI: 1.18-6.33)\}. HIV infection was associated with a decreased risk for diabetes in TB patients $\{\mathrm{OR}$ 0.41 (CI: 0.21-0.79)\}.

After controlling for other factors, age $>44$ years $\{\mathrm{OR} 4.52$ (95\% CI: 1.28-15.89)\}, any symptom for diabetes \{OR 1.89 (95\% CI: $1.05-3.42)\}$ and a family history of diabetes \{OR 3.42 (95\%: 1.88-6.21)\} were associated with an increased risk for DM. While HIV infection \{OR 0.35 (95\% CI 0.17-0.73)\} seemed to decrease the risk of diabetes in TB patient.

\section{Discussion}

This descriptive cross-sectional study was conducted among patients attending routine clinics for TB, in Dar 
Table 3 Factors associated with diabetes

\begin{tabular}{|c|c|c|c|}
\hline Characteristic & $\begin{array}{l}\text { Diabetes } \\
n=64\end{array}$ & Total & $P$-value \\
\hline \multicolumn{4}{|l|}{ Sex } \\
\hline Male & $43(10.3 \%)$ & $416(63.0 \%)$ & \\
\hline Female & $21(8.6 \%)$ & $244(37 \%)$ & 0.499 \\
\hline \multicolumn{4}{|l|}{ Age group in years } \\
\hline$\leq 24$ & $3(3.4 \%)$ & $87(13.2 \%)$ & \\
\hline $25-34$ & $10(5.5 \%)$ & $181(27.4 \%)$ & \\
\hline $35-44$ & $16(9.3 \%)$ & $172(26.1 \%)$ & 0.001 \\
\hline$>44$ & $35(15.9 \%)$ & $220(33.3 \%)$ & \\
\hline \multicolumn{4}{|l|}{ Marital status } \\
\hline Never married & $11(5.9 \%)$ & $188(28.5 \%)$ & \\
\hline Married & $43(12.1 \%)$ & $355(53.8 \%)$ & 0.057 \\
\hline Divorced & $10(8.5 \%)$ & $117(17.7 \%)$ & \\
\hline \multicolumn{4}{|l|}{ Education level } \\
\hline No formal education & $3(4.6 \%)$ & $65(9.8 \%)$ & \\
\hline Primary & 47 (10.9\%) & $430(65.2 \%)$ & 0.32 \\
\hline Secondary & $9(7.4 \%)$ & $121(18.3 \%)$ & \\
\hline College & $5(11.4 \%)$ & $44(6.7 \%)$ & \\
\hline \multicolumn{4}{|l|}{ Occupation } \\
\hline Unemployed & $11(7.6 \%)$ & $145(22.0 \%)$ & \\
\hline Employed & 49 (10.1\%) & $484(73.3 \%)$ & 0.708 \\
\hline Retired & $4(12.9 .3 \%)$ & $31(4.7 \%)$ & \\
\hline \multicolumn{4}{|l|}{ Family history of diabetes } \\
\hline Yes & $24(20.7 \%)$ & $116(17.6 \%)$ & \\
\hline No & $40(7.4 \%)$ & $544(82.4 \%)$ & $<0.001$ \\
\hline \multicolumn{4}{|l|}{ Cigarette smoking } \\
\hline Ever smoked & $18(10.0 \%)$ & $180(27.3 \%)$ & \\
\hline Never smoked & $46(9.6 \%)$ & $480(72.7 \%)$ & 0.69 \\
\hline \multicolumn{4}{|l|}{ Alcohol use } \\
\hline Ever used & $26(9.7 \%)$ & $267(40.5 \%)$ & \\
\hline Never used & $38(9.7 \%)$ & $393(59.5 \%)$ & 0.791 \\
\hline \multicolumn{4}{|l|}{ Body mass Index $\mathrm{Kg} / \mathrm{M}^{2}$} \\
\hline Underweight & $13(7.5 \%)$ & $173(26.3 \%)$ & \\
\hline Normal & $34(8.5 \%)$ & $398(60.4 \%)$ & 0.031 \\
\hline Overweight & $12(18.2 \%)$ & $66(10.0 \%)$ & \\
\hline Obesity & $4(18.2 \%)$ & $22(3.3 \%)$ & \\
\hline \multicolumn{4}{|l|}{ HIV sero-status } \\
\hline Negative & $53(11.8 \%)$ & $448(68 \%)$ & \\
\hline Positive & $11(5.2 \%)$ & $212(32 \%)$ & 0.007 \\
\hline
\end{tabular}

es Salaam. We found that about $10 \%$ of patients receiving TB treatment had DM which is higher than the estimated prevalence of 3.5 and $4.3 \%$ among adults aged 20-79years in the general population [3, 21]. Similar prevalence rates of $\mathrm{DM}$ among $\mathrm{TB}$ patients have been reported in recent studies conducted in sub Saharan Africa [22-27] and elsewhere. Indeed, a review of several studies and a meta-analysis study on screening for DM among $\mathrm{TB}$ patients concluded that $\mathrm{DM}$ was associated with increased risk of TB [8].

Noteworthy however, is the fact that two thirds (60\%) of our study participants with DM did not know they had diabetes (diagnosis of DM was a result of this study). These findings are in keeping with reports from several other studies $[4,21,27,28]$ and lend support to the recommendation that TB patients be screened for diabetes as T2DM is often asymptomatic and frequently presents initially with complications. Indeed, reports from the IDF show that more than two thirds of adults with T2DM are not aware they have the disease [3]. In spite of these reports, DM screening is not standard of care among TB patients in most settings in sub Saharan Africa and elsewhere.

Findings from this study show that TB patients aged 44 years and above had four-fold increased risk of diabetes. Likewise, TB patients with family history of DM had a threefold increased risk of diabetes. Findings similar to these have been reported elsewhere [24]. Our study findings do not advocate DM screening for all TB patients but instead suggest that TB patients aged 44 years and above and those with positive family history, should be screened for diabetes mellitus.

Untreated DM is known to be a risk factor for poor TB outcomes that include treatment failure, relapse and death. In addition, published data indicate that diabetic patients are likely to remain sputum smear positive for AFB for 2 to 3 months following treatment for TB [29]. In another study $22 \%$ of the diabetic TB patients remained sputum culture positive after 6 months treatment course with TB medications [22].

Screening of TB patients for DM should therefore identify patients who need extra attention and care for better TB treatment outcomes and prevention of complications related to untreated DM.

Over $23 \%$ of TB patients in this study had impaired fasting glucose (IFG) for which we are not able with certainty to explain the cause. However, IFG may be indicative of stress- induced hyperglycemia that would disappear after TB treatment [30-32] but it may also be indicative of high risk to developing DM.

We did not follow up the study participants with impaired glucose tolerance to determine if the impaired glucose tolerance detected was TB induced hyperglycemia or was an indicator of later development of DM. Due to the study design we are not able to establish what started first if it was DM or TB. Nonetheless, results of this study indicate that about a quarter $(23 \%)$ of TB patients had IFG that may have been stress-induced, by the TB disease or an indicator of developing DM in 
Table 4 Predicators for diabetes among TB patients

\begin{tabular}{|c|c|c|c|c|}
\hline Predictor & Univariate Analysis Odds Ratio (95 Cl) & $P$ value & Multivariate Analysis Odds Ratio (95 Cl) & $P$ value \\
\hline \multicolumn{5}{|l|}{ Sex } \\
\hline Female & 1 & & 1 & \\
\hline Male & $1.22(0.71-2.12)$ & 0.469 & $1.07(0.58-1.97)$ & 0.837 \\
\hline \multicolumn{5}{|l|}{ Age } \\
\hline$<24$ & 1 & & 1 & \\
\hline $25-34$ & $0.19(0.06-0.63)$ & 0.007 & $1.59(0.41-6.15)$ & 0.500 \\
\hline $35-44$ & $0.31(0.15-0.64)$ & 0.002 & $3.22(0.87-11.94)$ & 0.080 \\
\hline$>44$ & $0.54(0.29-1.02)$ & 0.056 & $4.52(1.28-15.89)$ & 0.018 \\
\hline \multicolumn{5}{|c|}{ Any DM symptom } \\
\hline No & 1 & & 1 & \\
\hline Yes & $2.25(1.33-3.18)$ & 0.003 & $1.89(1.05-3.42)$ & 0.034 \\
\hline \multicolumn{5}{|l|}{ Weight loss } \\
\hline No & 1 & & & \\
\hline Yes & $1.05(0.59-1.88)$ & 0.871 & & \\
\hline \multicolumn{5}{|l|}{ Fatigue } \\
\hline No & 1 & & & \\
\hline Yes & $1.29(0.76-2.21)$ & 0.335 & & \\
\hline \multicolumn{5}{|l|}{ Blurred Vision } \\
\hline No & 1 & & 1 & \\
\hline Yes & $2.45(1.36-4.44)$ & 0.003 & $1.60(0.82-3.13)$ & 0.170 \\
\hline \multicolumn{5}{|l|}{ Family history } \\
\hline No & 1 & & 1 & \\
\hline Yes & $3.29(1.89-5.71)$ & $<0.001$ & $3.42(1.88-6.21)$ & $<0.001$ \\
\hline \multicolumn{5}{|l|}{ Ever Smoked } \\
\hline No & 1 & & & \\
\hline Yes & $1.05(0.59-1.86)$ & 0.872 & & \\
\hline \multicolumn{5}{|c|}{ Alcohol consumption } \\
\hline No & 1 & & & \\
\hline Yes & $1.01(0.59-1.70)$ & 0.977 & & \\
\hline \multicolumn{5}{|l|}{ Body Mass Index } \\
\hline Underweight & 1 & & 1 & \\
\hline Normal & $1.15(0.59-2.24)$ & 0.681 & $0.87(0.43-1.75)$ & 0.689 \\
\hline Overweight & $2.73(1.18-6.33)$ & 0.019 & $1.73(0.69-4.33)$ & 0.242 \\
\hline Obesity & $2.73(0.81-9.28)$ & 0.107 & $2.15(0.57-8.03)$ & 0.256 \\
\hline \multicolumn{5}{|l|}{ HIV sero-status } \\
\hline Negative & 1 & & 1 & \\
\hline Positive & $0.41(0.21-0.79)$ & 0.009 & $0.35(0.17-0.73)$ & 0.005 \\
\hline
\end{tabular}

the future. Such patients would benefit from regular blood sugar monitoring to detect early onset DM as well as appropriate changes in their lifestyle to prevent/delay onset of DM.

We observed that HIV sero-negative TB patients were more likely to have DM compared to those who were HIV sero-positive. Similar findings have been reported in other studies in SSA $[19,26,33]$. However, published reports on association between HIV and diabetes have not been consistent. A nationwide population based cohort study in Denmark found that HIV infected people not on HAART were not at increased risk of developing DM [34]. On the other hand a study from the USA reported increased risk of DM among HIV infected 
persons on treatment [35]. A meta-analysis on the relationship between HIV and DM in SSA concluded that there was no association between the two conditions [36].

Further studies are needed to examine the effects of CD4 cell count level HIV antiretroviral regimens, and obesity among TB HIV co-infection and DM.

There was a trend that indicated that overweight and obese individuals had an increased risk for development of DM, however due to small numbers of participants with overweight and obesity statistical significance could not be achieved.

The results of this study indicate that screening for DM among patients attending public TB clinics in Dar es Salaam was possible and led to detection of patients with unknown DM and impaired glucose intolerance. Furthermore, DM screening should be targeted to TB patients aged 44 years or more and those with a family history of DM. Nonetheless, similar studies need to be done to confirm our findings before policy change can be considered.

\section{Conclusion}

Diabetes mellitus is a common co-morbidity in TB patients. Integration of diabetes screening particularly in TB patients aged 44 years and above and/or in patients with a family history of DM at TB clinics offers an opportunity for screening of patients who may have not otherwise presented to medical care. HIV sero-negative TB patients were more likely to have DM compared to those who were HIV sero-positive. Further studies are needed confirm this observation and the underlying reasons.

\section{Abbreviations \\ ADA: American diabetic association; AFB: Acid fast Bacilli; BMl: Body mass index; CD4: Cluster for differentiation; Cl: Confidence intervals; DM: Diabetes mellitus; HAART: Highly active antiretroviral therapy; HIV: Human immunodeficiency virus; IDF: International Diabetes Federation; IFG: Impaired fasting glucose; SSA: Sub-Saharan Africa; T2DM: Type 2 diabetes mellitus; TB: Tuberculosis}

\section{Acknowledgements}

We wish to acknowledge assistance from Prof F. Mugusi for his valuable input to the manuscript. Authors also wish to extend appreciation to patients for their willingness and cooperation and health care workers at participating tuberculosis clinics for their dedication.

\footnotetext{
Authors' contributions

Study design- HK and KP; field work and data acquisition -HK and KP; Data analysis and interpretation; HK, PJM and KP. Initial manuscript draft PJM, HK and KP, all authors contributed to the draft and approved the final manuscript.

\section{Funding}

This work was supported by Fogarty International Centre (Bethseda, MD, USA) through a grant number D4TW009573 for TB Research at Muhimbili University of Health and Allied Sciences TRIM-TB. Funding was for purchase of laboratory reagents, study equipment and travel to the study sites. There was no additional external funding received for this study.

The funder had no role in the design, analysis or final write up of the manuscript.
}

\section{Availability of data and materials}

Dataset used for analysis in this study are not publicly available, data are however available from the corresponding author on reliable request.

\section{Ethics approval and consent to participate}

All recruited participants were informed about the study details prior to enrollment and verbal consent was obtained from each study participant prior to enrollment in the study. Ethical approval was obtained from the Muhimbili University of Health and Allied Science institutional review board approval number MU/PGS/SAECNOI.XVI/.

\section{Consent for publication}

Not applicable.

\section{Competing interests}

The authors declare that they have no competing interests.

Received: 9 June 2018 Accepted: 9 October 2019

Published online: 29 October 2019

\section{References}

1. Guariguata L, Whiting D, Weil C, Unwin N. The International Diabetes Federation diabetes atlas methodology for estimating global and national prevalence of diabetes in adults. Diabetes Res Clin Pract. 2011;94(3):322-32.

2. Whiting DR, Guariguata L, Weil C, Shaw J. IDF diabetes atlas: global estimates of the prevalence of diabetes for 2011 and 2030. Diabetes Res Clin Pract. 2011;94(3):311-21.

3. International Diabetes Federation. IDF diabetes atlas. 7th ed. Brussels: idf.org; 2015

4. Dooley KE, Chaisson RE. Tuberculosis and diabetes mellitus: convergence of two epidemics. Lancet Infect Dis. 2009;9(12):737-46.

5. Mclarty DG, Kitange HM, Mtinangi BL, Makene WJ, ABM S, Masuki G, et al. Prevalence of diabetes and impaired glucose tolerance in rural Tanzania. Lancet. 1989;1(8643):871-5.

6. Aspray TJ, Mugusi F, Rashid S, Whiting D, Edwards R, Alberti KG, et al. Rural and urban differences in diabetes prevalence in Tanzania: the role of obesity, physical inactivity and urban living. Trans R Soc Trop Med Hyg. 2000;94(6):637-44.

7. Yorke E, Atiase Y, Akpalu J, Sarfo-Kantanka O, Boima V, Dey ID. The bidirectional relationship between tuberculosis and diabetes. Tuberc Res Treat. 2017;2017:1-6.

8. Jeon CY, Murray MB. Diabetes mellitus increases the risk of active tuberculosis: a systematic review of 13 observational studies. PLoS Med. 2008;5(7):1091-101.

9. Jawad F, Shera AS, Memon R, Ansari G. Glucose intolerance in pulmonary tuberculosis. J Pak Med Assoc. 1995;45(9):237-8 Available from: http://www. ncbi.nlm.nih.gov/pubmed/8683828.

10. Baker MA, Harries AD, Jeon CY, Hart JE, Kapur A, Lönnroth K, et al. The impact of diabetes on tuberculosis treatment outcomes: a systematic review. BMC Med. 2011;9(1):81 Available from: http://www.biomedcentral. com/1741-7015/9/81.

11. Yoon YS, Jung JW, Jeon EJ, Seo H, Ryu YJ, Yim JJ, et al. The effect of diabetes control status on treatment response in pulmonary tuberculosis: a prospective study. Thorax. 2017;72(3):263-70.

12. Senkoro M, Mfinanga S, Egwaga S, Mtandu R, Kamara DV, Basra D, et al. Prevalence of pulmonary tuberculosis in adult population of Tanzania: a national survey, 2012. Int J Tuberc Lung Dis. 2016;20(8):1014-21.

13. Harries AD, Lin Y, Satyanarayana S, Lönnroth K, Li L, Wilson N, et al. The looming epidemic of diabetes-associated tuberculosis: learning lessons from HIV-associated tuberculosis. Int J Tuberc Lung Dis. 2011;15(11):1436-44.

14. Balakrishnan S, Vijayan S, Nair S, Subramoniapillai J, Mrithyunjayan S, Wilson $\mathrm{N}$, et al. High diabetes prevalence among tuberculosis cases in Kerala, India. PLoS One. 2012;7(10):1-7.

15. Report of a WHO Expert Committee. Physical status: the use and interpretation of anthropometry. Technical report series no. 854. 1995.

16. Markowitz JS. Body mass index (BMI). In: SpringerBriefs in public health; 2018.

17. Association AD. Standards of medical care in diabetes-2014. Diabetes Care 2014;37(Suppl. 1):S14-80. https://doi.org/10.2337/dc14-S014

18. ADA. American Diabetes Association. Classification and diagnosis of diabetes. Diabetes Care. 2015;38(Suppl):S8-S16. 
19. Faurholt-Jepsen D, Range N, PrayGod G, Jeremiah K, Faurholt-Jepsen M, Aabye MG, et al. Diabetes is a risk factor for pulmonary tuberculosis: a casecontrol study from Mwanza, Tanzania. PLoS One. 2011;6(8):4-8.

20. Mickey RM, Greenland S. The impact of confounder selection criteria on effect estimation. Am J Epidemiol. 1989;129(1):125-37.

21. World Health Organization. Global report on diabetes. Book. 2016.

22. Mugusi F, Swai ABM, Alberti KGMM, McLarty DG. Increased prevalence of diabetes mellitus in patients with pulmonary tuberculosis in Tanzania. Tubercle. 1990;71(4):271-6.

23. Baldé NM, Camara A, Camara LM, Diallo MM, Kaké A, Bah-Sow OY. Associated tuberculosis and diabetes in Conakry, Guinea: prevalence and clinical characteristics. Int J Tuberc Lung Dis. 2006;10(9):1036-40.

24. Owiti P, Keter A, Harries AD, Pastakia S, Wambugu C, Kirui N, et al. Diabetes and pre-diabetes in tuberculosis patients in western Kenya using point-ofcare glycated haemoglobin. Public Heal Action. 2017:7(2):147-54.

25. Boillat-Blanco N, Ramaiya KL, Mganga M, Minja LT, Bovet P, Schindler C, et al. Transient hyperglycemia in patients with tuberculosis in Tanzania: implications for diabetes screening algorithms. J Infect Dis. 2016;213(7): 1163-72.

26. Kibirige D, Ssekitoleko R, Mutebi E, Worodria W. Overt diabetes mellitus among newly diagnosed Ugandan tuberculosis patients: a cross sectional study. BMC Infect Dis. 2013;13(1):1 Available from: BMC Infectious Diseases,

27. Damtew E, Ali I, Meressa D. Prevalence of diabetes mellitus among active pulmonary tuberculosis patients at St. Peter specialized hospital, Addis Ababa, Ethiopia. World J Med Sci. 2014;11(3):389-396.

28. Restrepo BI, Camerlin AJ, Rahbar MH, Wang W, Restrepo MA, Zarate I, et al. Cross-sectional assessment reveals high diabetes prevalence among newlydiagnosed tuberculosis cases. Bull World Health Organ. 2011;89(5):352-9.

29. Siddiqui AN, Khayyam KU, Sharma M. Effect of diabetes mellitus on tuberculosis treatment outcome and adverse reactions in patients receiving directly observed treatment strategy in India: a prospective study. Biomed Res Int. 2016;2016:7273935.

30. Singh MM, Biswas SK, Shah A. Impaired glucose tolerance in active pulmonary tuberculosis. Indian J Tuberc. 1984;31(3):118-121.

31. Oluboyo PO, Erasmus RT. The significance of glucose intolerance in pulmonary tuberculosis. Tubercle. 1990;71(2):135-8.

32. Lin Y, Yuan Y, Zhao X, Liu J, Qiu L, He X, et al. The change in blood glucose levels in tuberculosis patients before and during anti-tuberculosis treatment in China. Glob Health Action. 2017:10(1):1-7.

33. Ekeke N, Ukwaja KN, Chukwu JN, Nwafor CC, Meka AO, Egbagbe EE, et al. Screening for diabetes mellitus among tuberculosis patients in southern Nigeria: a multi-centre implementation study under programme settings. Sci Rep. 2017;7(February):1-8. https://doi.org/10.1038/srep44205.

34. Rasmussen LD, Mathiesen ER, Kronborg G, Pedersen C, Gerstoft J, Obel N. Risk of diabetes mellitus in persons with and without HIV: a Danish nationwide population-based cohort study. PLoS One. 2012;7(9):18-22.

35. Hernandez-Romieu AC, Garg S, Rosenberg ES, Thompson-Paul AM, Skarbinski J. Is diabetes prevalence higher among HIV-infected individuals compared with the general population? Evidence from MMP and NHANES 2009-2010. BMJ Open Diabetes Res Care. 2017:5(1):e000304.

36. Prioreschi A, Munthali RJ, Soepnel L, Goldstein JA, Micklesfield LK, Aronoff DM, et al. Incidence and prevalence of type 2 diabetes mellitus with HIV infection in Africa: a systematic review and meta-analysis. BMJ Open. 2017; 7(3):1-11.

\section{Publisher's Note}

Springer Nature remains neutral with regard to jurisdictional claims in published maps and institutional affiliations.

Ready to submit your research? Choose BMC and benefit from:
- fast, convenient online submission
- thorough peer review by experienced researchers in your field
- rapid publication on acceptance
- support for research data, including large and complex data types
- gold Open Access which fosters wider collaboration and increased citations
- maximum visibility for your research: over 100M website views per year
At BMC, research is always in progress.
Learn more biomedcentral.com/submissions

